\title{
Academic performance, childhood economic resources, and the choice to leave school at age sixteen ${ }^{*}$
}

\author{
Sholeh A. Maani * ${ }^{+}$, Guyonne Kalb ** \\ * Department of Economics, The University of Auckland, Private Bag 92019, Auckland, New Zealand \\ ** Melbourne Institute of Applied Economic and Social Research \\ The University of Melbourne, Victoria 3010, Australia
}

Received 5 March 2004; accepted 14 December 2005

+ Corresponding Author. Tel: +64 93737 599; fax: +64 93737427

E-mail address: s.maani@auckland.ac.nz (S.Maani)

\begin{abstract}
A general international observation is that adolescents from disadvantaged families are more likely to leave school at age 16. In this paper we extend the literature on school-leaving decisions by using a new and extensive panel data set from New Zealand; and by examining the effect of family income, and personal and environmental characteristics since childhood on both academic performance and subsequent schooling choices. Results obtained from single equations and joint estimation, allowing for possible endogeneity of academic performance, reveal the importance of the role of academic performance in models of demand for education. Several factors that are at work for a long time, such as household income at different points in time, influence the schoolleaving decision through academic performance. These results point to the role that stimulating academic performance may play in breaking cycles of disadvantage.
\end{abstract}

JEL Classifications: I21, J13, J24, J18

Key Words: Demand for education, endogeneity of academic performance, family resources 


\section{Introduction}

Early school leaving in many cases closes pathways to further education. In countries such as the U.K., Australia and New Zealand, and in many states of the U.S., where education is compulsory up to the age of sixteen, schooling choices at sixteen have lifetime economic impacts. ${ }^{1}$ A general observation is that adolescents from disadvantaged families are more likely to leave school at the time it ceases to be compulsory, and they are less likely to participate in university education. ${ }^{2}$

In this study, we extend the literature on the decision of school leaving by examining the link between academic performance and the choice to leave school. Our analysis uses a new panel data set from New Zealand that includes several variables usually not available in typical longitudinal data sets. These variables include childhood and adolescent family income, childhood IQ scores, and nationally comparable academic performance results at age 15. Our analyses include both single-equation and joint estimations, which allow for non-zero correlation between the unobserved terms in the academic performance and school-leaving equations. The results consistently show the importance of academic performance in school-leaving choices. This result is robust over alternative specifications.

Demand for post-compulsory education as a personal choice has been addressed by Willis and Rosen (1979), who estimate participation in university studies, and by Rice (1987), who estimates secondary school leaving in Britain. The question of the effect of parental resources on the academic performance of children and adolescents has received recent attention by, for example, Blau (1999), Feinstein and Symons (1999), and Ermisch and Francesconi (2001). ${ }^{3}$ This study extends this literature by estimating models of school leaving and academic performance, which incorporate potential endogeneity of academic performance, and the impact of family resources and a child's personal characteristics. The study allows personal and family resources 
throughout childhood to influence academic performance, which in turn can influence early school-leaving choices.

The Christchurch Health and Development Study (CHDS) data set used in this paper has several features making it particularly suitable for this type of study. ${ }^{4}$ First, it allows us to control for important longitudinal personal and household conditions starting from birth. The available information includes a measure of academic performance at age 15, which is standardized through the use of a national set of examinations. This measure, in particular, distinguishes this data set favorably from many other data sets. In addition, the large number and detail of available variables substantially reduce the 'unexplained' part of estimations due to unobserved heterogeneity. This is achieved by controlling for the factors that are related to personal academic ability and parental resources. The ability to distinguish between early childhood and teenage household income conditions is of interest in examining the effects of parental income at different points in time on academic performance and early school-leaving choices.

The primary and secondary educational systems in New Zealand are in many respects similar to the U.S. system and the systems in other English-speaking countries. In New Zealand, education, which starts with a kindergarten-equivalent year at age 5, continues for 12 years beyond the initial kindergarten year. Those who are at school in grades 10 and 12 are expected to take nationally administered examinations. Education is compulsory in New Zealand up to the age of 16. School Certificate Exams at the end of grade 10 are taken when students are 15 or 16 years old depending on their birth month. ${ }^{5}$ These nationally administered exams are based on the same set of questions and grading for all participants. This is a great advantage as the use of such a measure of academic performance eliminates problems with the potential inconsistency in comparing grades across schools in lower and higher income decile localities. The School 
Certificate results thus provide nationally comparable academic performance results (Grade Point Average (GPA) results) at around age 15 and prior to the potential school leaving at age 16. In contrast, for example, SAT scores (Scholastic Aptitude Tests) for College Entrance Examinations in the U.S. are given at the end of high school and could not be used in models of early school leaving. ${ }^{6}$

This nationally comparable measurement of academic performance, combined with our estimation approach, allows us to shed new empirical light on the effect of academic performance on school leaving. School leaving entails important policy implications. Other features of the CHDS dataset provide an opportunity to examine the links between school leaving of teenagers, their academic performance and family resources.

The plan of the paper is as follows. Section 2 provides a brief discussion of the data set and the characteristics of the sample. The analytical framework and econometric models are presented in Section 3, followed by a discussion of our results in Section 4. The analyses include singleequation and joint estimations of school leaving and academic performance. Concluding remarks are presented in Section 5.

\section{Data and characteristics of the sample}

The Christchurch Health and Development longitudinal Study (CHDS) includes extensive economic and academic information on a cohort born in Christchurch in 1977. This cohort is followed throughout their childhood and adolescence, providing information on their transition from school to further education, training and work.

Christchurch is the third largest city in New Zealand, an English speaking country. Christchurch has income and educational characteristics that resemble New Zealand national averages, but a 
higher proportion of the population (91.8\%) is from an English-speaking background, compared to the $80.1 \%$ at the national level. The population of Christchurch and its surrounding areas is under half a million, and the other ethnic groups in the population include Maori, Pacific Island and other Asian and European ethnic groups. Among the advantages of this data set is the extensive amount of information on the cohort's academic and home environments, academic performance and ability, and socio-economic background. In addition, while the data set follows a cohort and is localized by nature, it provides a rather rare and special opportunity in providing a natural control of general environmental, social, and political conditions for the entire sample. This characteristic of the data set is important for examining the impact of variables, such as family resources, on teenage academic performance and schooling choices.

The sample analyzed in this study utilizes information from the survey years between birth in 1977 to age 16 of the cohort, selecting respondents for whom data on all variables of interest were available. ${ }^{7}$ Columns 1 and 2 in Table 1 present mean characteristics of individuals in the sample and of those who continued with post-compulsory education. These characteristics include the individual's academic performance as reflected by the average School Certificate grade obtained; IQ score at age 8 (which is unknown to the individual); and the household income decile between ages 11 and 14, and in early childhood between ages 1 and 5 . In addition, the data set includes school, neighborhood and peer factors, such as the proportion of the student's class continuing to post-compulsory levels (at age 16) or association with peer groups with deviant behavior (measured on a 1 to 10 scale reflecting problems with the law, substance abuse, etc.). The latter is expected to serve as a proxy for the student's interest in deviant behavior. $^{8}$

\section{[ Table 1 about here ]}


The IQ variable is the total score at age 8 based on the Wechsler Intelligence Scale for Children (WISC) which tests the cognitive performance of children. It is an international test performed by qualified psychologists. The scores range from 70 to 145 . We expect that childhood cognitive tests reflect both innate ability and investments by parents in their children up to that time. It is useful to have this information in the models to predict future academic performance. ${ }^{9}$

As column 1 of Table 1 on the full sample shows, about half of the sample (50.5 per cent) was female. The characteristics of the sample on academic performance and economic conditions reflect the expected national averages, such as the average IQ score of 102.8 and the average school certificate grade of 1.06 (measured on a scale of 0 to 3 ), which is equivalent to a $\mathrm{C}$, the average national grade for these exams. Home ownership by parents was 88.6 per cent. The average proportion of family income from benefits was 13.9 per cent. In the sample, the ethnicity of 7.4 per cent was indigenous Maori and 2.8 per cent had Pacific Island ethnicity.

In relation to parental education, 49.8 per cent of the mothers and 47.5 per cent of the fathers of the respondents had no school qualifications (that is, less than the year 10 School Certificate), and 20.6 per cent of mothers and 19.5 per cent of fathers had tertiary (university or other post high school) qualifications.

In general, Table 1 shows that those who continued in post-compulsory education had mean characteristics which were different from the full sample. These differences included a higher average School Certificate grade, a higher average IQ score at age 8, a higher family income decile, their parents' education levels were higher, and they went to a school with a higher proportion of the class continuing to the post-compulsory $11^{\text {th }}$ grade. These characteristics are consistent with the hypothesis that individuals sort themselves into different choices based on 
their academic ability, the expected returns to their choice, family income constraints, and influences from the school and peer environment. Students from the lower income deciles are more likely to leave school early and less likely to participate in higher studies.

\section{Analytical framework}

This paper follows standard economic theory that models school leaving as a function of academic achievement, family resources and personal characteristics (Becker, 1993; Schultz, 1961). ${ }^{10}$ Academic achievement is a function of ability, personal characteristics and family resources, which includes many of the same factors that explain school leaving. In addition, some of the same unobservable individual or household characteristics may influence both academic performance and school leaving. This indicates the necessity of allowing for potential endogeneity of academic performance in the school-leaving model, through joint estimation of the equations for school leaving and academic performance.

Our empirical work follows from the extended framework in Willis and Rosen (1979) and Rice (1987) in which the decision to participate in higher education depends on the expected utility associated with each option. Following this theory, we posit that an individual's decision will depend on the expected benefits and costs of each option, as expressed by

$\operatorname{Pr} P C E_{i}=\operatorname{Pr}\left[\left(V_{i 1}-V_{i 0}\right)=G\left(A_{i}, X_{d i}\right)+\varepsilon_{d i}>0\right]$

where vectors of observables $A_{i}$ and $X_{d i}$ lead to participation in post-compulsory education $P C E_{i}$ if net benefits $V_{i 1}-V_{i 0}$ are positive. $V_{i j}$ are the expected benefits of option $j$ for individual $i$; $A_{i}$ represents academic performance for individual $i$ (representing ability, effort, and parental investments); and $X_{d i}$ represents personal, family and environmental characteristics. Assuming that the error term $\varepsilon_{d i}$ is normally distributed, equation 1 can be estimated via Probit analysis. 
The dependent variable in the school-leaving equation in this paper is binary, indicating whether or not the respondent had left school at the post-compulsory age of 16 . We expect academic performance to affect school leaving at age sixteen (in equation 3 below) directly. However, the assumption of exogeneity may be incorrect. Academic performance measures a mixture of academic ability, resources and effort. Therefore, when using academic performance to explain school leaving, the possibility of endogeneity should be investigated, since the school-leaving decision and academic performance could be determined by similar unobserved factors such as motivation. $^{11}$

To allow for endogeneity a joint model of academic performance and school leaving is estimated. Our joint (structural) model is specified as a set of two equations, estimated simultaneously (see for example Maddala, 1983):

$$
\begin{aligned}
& A_{i}^{*}=\alpha_{a}+X_{a i}{ }^{\prime} \gamma_{a}+\varepsilon_{a i} \\
& D_{i}^{*}=\alpha_{d}+X_{d i}{ }^{\prime} \gamma_{d}+A_{i} \delta_{d}+\varepsilon_{d i}
\end{aligned}
$$

where $A_{i}^{*}$ is the latent academic performance (estimated by Tobit to address censoring from below and above in $A_{i}^{*}$ ), and $D_{i}^{*}$ is the latent school leaving tendency (estimated by Probit). ${ }^{12,13}$ $X_{a i}$ represents personal, family and environmental characteristics. Error terms $\varepsilon_{a i}$ and $\varepsilon_{d i}$ have a bivariate normal distribution, with zero means, variances $\sigma_{1}^{2}$ and 1 , and correlation $\rho .{ }^{14}$ We are especially interested in whether the value and direction of $\delta_{\mathrm{d}}$ changes or diminishes in importance once endogeneity and a non-zero error correlation across the two equations are incorporated. We also estimate a joint reduced form of equations 2 and 3 with latent academic performance in equation 3 instead of observed academic performance, using a Tobit and Probit specification as in the structural model (see, for example, Stern 1989; and Cai and Kalb, 2005). 
The potential effect of school leaving on academic performance depends on the reason for school leaving. It could be positive for someone who wants to enter a trade or negative for someone with poor motivation. The effect of leaving out this direct effect on the structural coefficients is ambiguous. However, it should be noted that the joint reduced form implicitly accounts for this direct effect.

A challenge in identifying our system of equations is that most of the factors expected to influence academic performance are also expected to influence the school-leaving choice. However, in this data set, the IQ score measured at age 8 provides an exclusion restriction for equation 3. Theoretically speaking, it is reasonable to assume that the later observed academic performance (known by the student and others involved) is a better approximation of personal talent, ability and effort and thus a more appropriate predictor of school-leaving choices than IQ. Therefore, once the more recent academic performance measure is included in the model, it would be unlikely for the childhood IQ to exert an additional and independent effect on school leaving at age 16. That is, the observed academic performance $\left(\mathrm{A}_{\mathrm{i}}\right)$ incorporates the effect of academic ability, as measured by childhood IQ, and it also contains additional information beyond ability, such as effort. This assumption is empirically verified in the results section. Excluding IQ helps to identify the system in addition to the non-linear transformation of latent academic performance to observed academic performance, which is censored at 0 and 3 .

The measures of parental income we include reflect permanent rather than current income, providing a measure of long-term parental resources (see Blau, 1999, for U.S. evidence). In addition, the data allow us to distinguish between parental income effects during early childhood and adolescent years on later academic performance and school-leaving choices. We use data on income decile, as a measure which is more universally recognizable and relevant to policy by 
reflecting information on income and relative deprivation. ${ }^{15}$ The two income measures are correlated, but the correlation is only 0.55 . Thus, each measure provides some independent information on the financial history of the household.

\section{Results}

All models in the following subsections are estimated on a sample for which information on all variables in any of the models is available. The first two subsections describe the results of estimating (2) and (3) separately while the third subsection discusses the joint results.

\subsection{School leaving at age 16}

Results for the school-leaving (dropout) equation in the last three columns of Table 2 show that academic performance has a significant effect on the early school-leaving decision. Based on the estimated coefficients in Table 2, marginal effects have also been calculated. ${ }^{16}$ For example, a policy that could improve the academic performance of students by one point of a grade would reduce the probability of leaving school at age 16 significantly by 4.3 percentage points on average across the sample. This is a substantial decrease, given the mean predicted dropout rate of 6.2 per cent. At a practical level, policies aimed at improving academic performance may be multifaceted, among which educators would emphasize assistance with homework or the provision of a place for children from disadvantaged families to do their homework. The estimates further show that, keeping other factors constant, females were much less likely to drop out of school, which may be related to fewer women going into employment in a trade or apprenticeship. Once academic performance and peer and school effects are included in the dropout model, few other variables are significant.

\section{[ Table 2 about here ]}


Similar to the finding by Duncan, Yeung, Brooks-Gunn \& Smith (1998), early income deciles have a greater effect on school leaving than later income deciles. With the inclusion of variables on academic performance, the proportion of family income from benefits, and school and peer effects from age 15; the income decile for adolescent years has no additional direct effect on school leaving. However, early childhood income shows a nearly significant direct effect on school leaving of about 0.1 percentage point for one decile increase. The effect is opposite to expectations and is discussed further in the next subsection. The finding is consistent with the hypothesis that conditional on academic performance, children from wealthier families, who do not know what they want to do and who do not like school, may be given more lee-way or options to drop (temporarily) out of school.

\subsection{Academic performance}

The results of the single equation for academic performance in the first three columns of Table 2 show that both early childhood and adolescent parental income deciles are important (and highly significant) in explaining academic performance. This may explain the counterintuitive effect of income on school leaving. The raw correlation between school leaving and the average income deciles is negative. The relationship only becomes positive after controlling for several other characteristics. Income may work through academic performance rather than directly affect the school-leaving decision. The effect of moving up one decile in the recent income measure (averaged over the time when the respondent was aged between 11 and 14) is estimated to be equivalent to 0.054 of a grade in the exams. In addition to this effect, moving up one early childhood income decile explains an additional effect of about 0.035 of a grade. ${ }^{17}$ Therefore, keeping other factors constant, together the predicted effect of the income decile variables is 0.089 of a grade difference for 1 decile increase. Over ten deciles, this could be close to the 
difference between a C and a D average grade, for example. The results found here are consistent with the effect of poverty (Duncan et al., 1998), the positive effect of income in many U.S. studies (Haveman and Wolfe, 1995), and Gregg and Machin’s (1998) finding on the effect of financial difficulties in early or late childhood. However, the finding by Duncan et al. (1998), that only early childhood parental income is significant in explaining the years of completed schooling and high school completion, is not repeated here for academic performance. The results are further consistent with recent results for the U.K. regarding the importance of resources throughout childhood in determining children's academic performance (Feinstein and Symons, 1999; Ermisch and Francesconi, 2001).

Our results are in contrast to Blau's (1999) study examining the effect of parental current and permanent income for early childhood development. Blau finds that 'family background and other family and child characteristics often have larger effects on child development, ... than does income ...' (p. 273). One of the differences between his study and our study is that the average age at which the child development scores are measured in his study is 5.7 years, compared to 15 to16 years in our study. ${ }^{18}$

As the results in Table 2 show, childhood scholastic performance, as reflected by the IQ test score at age eight, is also important. Each additional unit of the IQ score is associated with an increase of 0.027 of a grade. This is a large effect considering the range of IQ scores. The mean IQ score was 102.8 with a standard deviation of 14.8. This highlights the importance of the respondent's childhood scholastic ability in predicting academic performance in later years. Comparing this effect to the combined effect of the two income decile variables, we see that one income decile is equivalent to slightly more than 3 IQ units. To the extent that these childhood scholastic performance results may reflect early childhood parental investments in children's 
learning, the separate effect of income in the household during childhood is of interest.

\subsection{Joint estimates}

Results of the joint estimation of equations 2 and 3, and the joint reduced form estimation are presented in Tables 3 and 4. In the joint model, the direct effect of academic performance on school-leaving choices becomes more important, its coefficient increasing from -0.7107 to -1.3091 (see Tables 2 and 3). Thus, joint estimation strengthens the earlier finding on academic performance, showing that the earlier results concerning the importance of academic performance in school-leaving choices are robust. In addition, the effects of family income and other significant variables on academic performance are robust across the single-equation and joint estimations.

\section{[ Table 3 about here ]}

A second result of interest is that error correlation across the two equations is positive, indicating that after controlling for all the characteristics in the model, the unobserved heterogeneity is no longer negatively correlated. Where there are few variables of relevance available for inclusion in the model, the expectation is that the effects of unobserved ability or motivation and effort would introduce a negative component to the error correlation. This expectation is based on similar unobserved factors having a positive effect on the average academic performance score and a negative effect on the dropout probability. This is precisely what happens when the direct effect of academic performance is excluded from the school-leaving equation as can be seen in Table 4. The reduced-form joint model results in a significantly negative error correlation $(\rho=-0.223)$. This is the outcome we would expect if the error terms contained important unobserved characteristics related to the schooling decision, such as ability, motivation or effort. ${ }^{19}$ This is further support for the earlier finding regarding the importance of including academic 
performance as a factor which directly influences schooling choices by young adults.

The positive correlation between the error terms in the model based on equations 2 and 3 could be explained by a few factors as discussed in Section 3. First, it is consistent with some school leavers moving into training programs for which high academic scores may be required. Estimating the model with a slightly altered specification, redefining school leavers as those who are no longer in school or in a training or apprenticeship program, supports the apprenticeship effect hypothesis, as the error correlation decreases to $\rho=0.39$ in this specification (a decrease of about $25 \%$ from $\rho=0.51$ ). The effects of other characteristics remain similar to the results presented in Table 3. Additionally, the error terms may contain unobserved traumatic effects. For example, students who had performed unexpectedly poorly in their exams due to an exogenous (and unobserved) incident such as an accident, illness, or emotional trauma before the exams could have had lower than expected exam grades (a negative error term in equation 2). However, due to long-term choices they would have been likely to continue with their postcompulsory education regardless of their low exam score, resulting in a lower than expected dropout rate (a negative error term in equation 3).

The results for the reduced-form joint model, which excludes the explicit direct effect of academic performance, are shown in Table 4. For comparison, the direct effect of academic performance can be derived from these reduced-form results using early childhood ability as reflected by the IQ score at age eight to identify the system. Calculating the direct effect of $A_{i}$ from the transformed joint reduced-form parameters in Table 4, we find a coefficient of -0.84 , which lies in between the direct effect found in the single equation and the previous joint model. This is consistent with the expectation that the negative error correlation in the reduced-form model is caused by the large negative value of the direct effect of academic performance, as can 
be derived from the relationships between the old and transformed parameters. That is, the true correlation in the underlying structural model is positive as in the other specification of the joint model.

\section{[ Table 4 about here ]}

In the joint model, the coefficient of early childhood family income decile in the reduced-form school-leaving equation is no longer significant at the 5 per cent level, and the effect of more recent income is negative although insignificant. This shows that the negative effect of income on school leaving is through academic performance, but not directly. ${ }^{20}$ This result is consistent with the hypothesis that conditional on a specific level of academic performance, higher family income could provide an alternative to going to school. However, this effect is no longer statistically significant in the joint estimation.

Comparing the results for the academic performance model on other aspects, the results are generally similar across the reduced-form and the structural joint estimations. The reduced-form school-leaving component of the model, however, provides greater differences in results, compared to the structural joint specification. To make a proper comparison of the implications of the three models, marginal effects are presented in Tables 2, 3 and 4 for the exogenous variables. The marginal effects allow for direct and indirect effects of characteristics. For example, the marginal effects show that the effect of IQ is understated, and the effect of living in a rural area is overstated in the single-equation school-leaving model, because the indirect influences through academic performance are not recognized. ${ }^{21}$

These results consistently support the theory that parental resources and personal ability influence academic performance, which in turn determines schooling choices. The joint estimations further show that the effect of academic performance on school-leaving choices is robust across different 
model specifications. We also examined the sensitivity of the coefficients in Table 3 to an alternative specification of the joint model with IQ included in the school-leaving equation 3 (see the discussion in Section 3 on page 9). This alternative version is in principle identified through the non-linear transformation of the latent academic performance variable. The coefficients of interest, such as income decile, early income decile and IQ at age 8 (in the academic-performance equation) are robust to this change in specification (exhibiting only minor changes in the coefficients and marginal effects). Thus, the conclusions are not sensitive to the alternative specification. The IQ coefficient in the school-leaving equation is found to be small and insignificant (0.006 with a t-value of 0.53 and a likelihood ratio test statistic of only 0.26 ), when academic performance is also present in the school-leaving equation. Thus, the null hypothesis of the IQ parameter being zero could not be rejected at any sensible significance level. This test confirms that IQ (which is unknown to the child, their parents or teachers) is strongly correlated with academic performance at age 15, but beyond the effect through academic performance, it does not have an independent effect on school leaving. This confirms its choice as an instrument.

We also tested whether there was evidence of selection bias in the academic performance equation due to students leaving school before the exam. The results, reported in Maani and Kalb (2005), indicate that selection bias is not an issue.

Finally, the results highlight the need for joint estimation to assess the role of different variables properly when the endogenous academic performance measure is included as well. It also shows that academic performance explains more than childhood IQ and family resources on their own, and seems to have a direct effect on the school-leaving decision. 


\section{Conclusion}

This study has provided empirical evidence on the effect of personal characteristics and family resources since childhood on the academic performance of teenagers and their choices regarding leaving secondary school or continuing with post-compulsory education at age 16 . The schoolleaving choice is an important decision since it generally determines further higher education options and has lifetime income effects.

The study shows that the school-leaving decisions at age 16 are influenced by factors that are at work over a long period of time. This means policies aimed at retaining students at school should target children from a young age onwards. Personal ability, household income constraints and socio-economic background are all influential in school-retention choices. They exert an influence through factors such as academic performance, parental income, and school and peer effects. The results further show consistently the importance of including academic performance as an explanatory variable in models of demand for education. For example, the estimates from the single equation predict that policies that can improve the academic performance of students by one point of a grade would improve the student's probability of school retention at age 16 significantly by 4.3 percentage points. That is, the average probability of school leaving would be reduced from 6.2 per cent to 1.9 per cent. This indicates that if academic performance could be targeted in policies, for example, through providing assistance with homework or study for children from disadvantaged families, this could improve school retention.

Examining the determinants of academic performance at age 15, it is shown that it is not only influenced by parental income and resources, as reflected by the recent income decile, but also by

early childhood income resources. The estimated coefficient of the latter is about two thirds of the coefficient size of the more recent income decile variable. This result, in addition to the effect 
of the mother's school qualifications and childhood IQ, highlights the long-term nature of the early school-leaving decision process, the outcome of which is observed at age 16 . This result is consistent with recent results for the U.K. regarding the importance of early childhood resources in determining children's academic performance (Feinstein and Symons, 1999; Ermisch and Francesconi, 2001). This result is further consistent with results on the direct effect of early childhood resources on the probability of school leaving in the U.S. (Duncan et al., 1998). This clearly points to the need for long-term solutions to improve school retention of children from disadvantaged families.

A feature of this paper has been to compare single-equation estimations of academic performance and school leaving to joint estimations of academic performance and school leaving. We find that the results of interest are robust across the various estimation methods, and they support the relevance of including measures of academic performance in models of school leaving. There is a direct effect from academic performance on school leaving in addition to the simultaneous effect of other observable and unobservable characteristics. One variable for which the differently specified models have different implications is childhood IQ. The results indicate that accounting for the indirect effect of IQ through academic performance is important to properly assess the importance of IQ in a model that includes academic performance as an explanatory variable.

In conclusion, the results are consistent with the hypothesis that students sort themselves into schooling choices at age 16, based on the expected returns to these choices, their tastes, and information available to them through their family, school and peer networks. In the schoolleaving choice, the student's academic performance is an important channel through which personal ability and economic factors exert their influence. With regard to the economic factors, the influence seems to be through academic performance rather than directly. To the extent that 
the academic performance of students can be influenced throughout their education years, these results point to the role that childhood and teenage academic performance can play in breaking cycles of disadvantage.

\section{Acknowledgements}

We are grateful to Glen Cain, Bob Haveman, Barbara Wolfe, Charles Brown, Stephen Jenkins, John Ermisch, Lawrence Kahn, John Bound, John Karl Scholz, Donggyu Sul, seminar participants at the Australasian Econometric Society Meeting (ESAM 2002) and three anonymous referees for valuable comments. Special thanks go to Drs David Fergusson and John Horwood for making the data set available and for insightful information on the data set, and to Adam Warner at the University of Auckland for research assistance.

\section{References}

Anderson, D. S. and Vervoon, A. E. (1983). Access to privilege: patterns of participation in Australian post-secondary education, Canberra: Australian National University Press.

Becker, G. S. (1993). Human capital, third edition, Chicago University Press.

Blau, D. M. (1999). The effect of income on child development. Review of Economics and Statistics, 81 (2), 261-276.

Cai, L. and Kalb, G. (2005). Health status and labour force participation: Evidence from the HILDA data, forthcoming in Health Economics.

Case, A. C. and Katz, L. F. (1991). The company you keep: The effects of family and neighborhood on disadvantaged youths. NBER Working Paper 3705.

Duncan, G. J., Yeung, W. J., Brooks-Gunn, J. \& Smith, J. (1998). How much does child poverty affect the life chances of children? American Sociological Review, 63, 406-23.

Ermisch, J. and Francesconi, M. (2001). Family matters: Impact of family background on educational attainment. Economica, 68(270), 137-156.

Evans, W. N. and Schwab, R. M. (1995). Finishing high school and starting college: Do Catholic schools make a difference? Quarterly Journal of Economics, 110 (4): 941-974.

Feinstein, L. and Symons, J. (1999). Attainment in secondary school. Oxford Economic Papers, 
51, 300-321.

Fergusson, D. M., Horwood, L. J. and Lloyd, M. (1991). Confirmatory factor models of attention deficit and conduct disorder. Journal of Child Psychology and Psychiatry, 32(2), 257-274.

Fergusson, D. M. and Lynskey, M. T. (1993). Maternal age and cognitive and behavioural outcomes in middle childhood. Paediatric and Perinatal Epidemiology, 7, 77-91.

Fuller, W. C., Manski, C. F., and Wise, D. A. (1982). New evidence on the economic determinants of postsecondary schooling choices. Journal of Human Resources, 17 (4): 477498.

Gregg, P. and Machin, S. (1998). Child development and success or failure in the youth labor market. Centre for Economic Performance Discussion Paper: No 397, London School of Economics.

Hanushek, E. A. (1979). Conceptual and empirical issues in the estimation of educational production functions. Journal of Human Resources, 14(3), 351-388.

Haveman, R. and Wolfe, B. (1995). The determinants of children's attainment: A review of methods and findings. Journal of Economic Literature, 33, 1829-78.

Light, A. and Strayer, W. (2000). The determinants of college completion: School quality or student ability? Journal of Human Resources, 35 (2): 299-332.

Maani, S. A. (1997). Investing in minds: The economics of higher education in New Zealand, (209 pp.). Wellington: Institute of Policy Studies Press.

Maani, S. A., (2004). Why have Maori relative income levels deteriorated over time? Economic Record, 80 (248), 100-123.

Maani, S. A. and Kalb, G. (2005). Academic performance, parental income, and the choice to leave school at age sixteen. University of Auckland, Department of Economics Working Paper No. 258.

Maddala, G. (1983). Limited dependent and qualitative variables in econometrics, New York: Cambridge University Press.

Maloney, T. (1999). An analysis of representative-ness and attrition in the CHDS, Wellington: New Zealand Treasury Working Paper, September.

Montgomery, J. (1991). Social networks and labor market outcomes: Toward an economic analysis. American Economic Review, 81(5), 1408-1418.

Prior, H. and Beggs, J. J. (1989). Influence of family background on the educational and labor force outcomes of year 12 school-leavers. Australian Journal of Statistics, 31A, 99-124.

Rice, P. G. (1987). The demand for post-compulsory education in the U.K. and the effects of educational maintenance allowances. Economica, 54, 465-475.

Rumberger, R.W. and Lamb, S. P. (2003). The early employment and further education 
experience of high school dropouts: A comparative study of the United States and Australia. Economics of Education Review, 22 (4), 353-366.

Schultz, T. W. (1961). Investment in human capital. American Economic Review, 51, 1-17.

Stern, S. (1989). Measuring the effect of disability on labor force participation. Journal of Human Resources 24(3), 361-395.

Williams, T. (1987). Participation in education. Hawthorn, Victoria: Australian Council for Educational Research, Research Monograph No. 30.

Willis, R. J. and Rosen, S. (1979). Education and self-selection. Journal of Political Economy, 87, S7-S38. 


\section{Table 1}

\section{Characteristics of the sample}

\section{Characteristics}

Mean

(Standard deviation)

$\begin{array}{cc}\text { Full } & \begin{array}{c}\text { Continued with } \\ \text { sample } \\ \text { post-compulsory } \\ \text { education }\end{array}\end{array}$

\section{Personal characteristics}

Female (\%)

$50.5 \% \quad 52.6 \%$

Maori ethnicity (\%)

$7.4 \% \quad 5.7 \%$

Pacific island ethnicity (\%)

$2.8 \%$

$2.3 \%$

IQ (tested at 8 years of age)

$102.8 \quad 105.8$

(14.88) (13.63)

\section{Education}

Average school certificate grade point average

(age 15 and $10^{\text {th }}$ grade, where Fail $=0, C=1, B=2, A=3$ )

1.061

1.26

Mother without qualifications ( $<10^{\text {"II }}$ grade)

$49.8 \%$

Mother with a tertiary qualification

$20.6 \%$

$43.6 \%$

Father without qualifications $\left(<10^{\text {mn }}\right.$ grade)

$47.5 \%$

$24.6 \%$

Father with a tertiary qualification

$19.8 \%$

$41.3 \%$

Total dropout rate from school at age 16

$15.5 \%$

$23.2 \%$

Dropout rate from school before exams

$8.8 \%$

Family and social environment

Adolescent average income decile: ages 11-14

(10 is the most affluent decile)

5.53

(2.54)

5.92

Early childhood average income decile: ages 1-5

5.82

(2.40)

Own their home (\%)

$88.6 \%$

Number of siblings

1.48

92.1\%

Rural location (\%)

$15.9 \%$

1.47

Proportion of family income from benefits

0.139

Regional unemployment rate

$10.6 \%$

$16.0 \%$

Proportion of respondents class continue at age 16

0.836

$(0.162)$

Average class size

28.8

(4.20)

0.106

$10.6 \%$

2.30

(2.45)

0.864

Association with deviant peers age 15

(10 is the highest association) 


\section{Table 2}

\section{Academic performance and school leaving, single equations}

(Equation (2): Ave_grade (National Exam Grade at age 15))

(Equation (3): Dropout: 1=Left school at Age 16; 0=Enrolled in school at age 16)

\begin{tabular}{|c|c|c|c|c|c|c|}
\hline \multirow[t]{2}{*}{ Explanatory variables } & \multicolumn{3}{|c|}{$\begin{array}{c}\text { Average_grade } \\
\text { (Tobit) }\end{array}$} & \multicolumn{3}{|c|}{$\begin{array}{l}\text { Dropout } \\
\text { (Probit) }\end{array}$} \\
\hline & Coefficient & z-value & $\begin{array}{c}\text { Marginal } \\
\text { effects }^{\mathrm{a}}\end{array}$ & Coefficient & z-value & $\begin{array}{c}\text { Marginal } \\
\text { effects }^{\mathrm{a}}\end{array}$ \\
\hline \multicolumn{7}{|l|}{ Direct effect: } \\
\hline Ave_grade & & & & $-0.7107 * * *$ & -4.14 & -4.3134 \\
\hline \multicolumn{7}{|l|}{ Personal characteristics } \\
\hline Female & $0.1845 * *$ & 2.97 & 0.1639 & $-0.6975 * *$ & -2.76 & -6.4335 \\
\hline Maori & 0.1054 & 0.94 & 0.0942 & 0.3278 & 1.00 & 3.5328 \\
\hline Pacific Islander & -0.1099 & -0.63 & -0.0968 & -0.2421 & -0.47 & -1.9633 \\
\hline IQ at age 8 & 0.0299 & 14.12 & 0.0266 & & & \\
\hline Mother_no_qualifications & $-0.1404 * *$ & -2.18 & -0.1255 & 0.2184 & 0.92 & 1.9844 \\
\hline Mother tert_qualifications & 0.1172 & 1.57 & 0.1052 & -0.1920 & -0.51 & -1.6328 \\
\hline Father_no_qualifications & -0.0376 & -0.60 & -0.0334 & 0.1497 & 0.65 & 1.3823 \\
\hline Father_tert_qualifications & 0.1351 & 1.71 & 0.1215 & 0.0595 & 0.16 & 0.5623 \\
\hline Income_decile(ages 11-14) & $0.0610 * * *$ & 4.06 & 0.0544 & 0.0107 & 0.17 & 0.0991 \\
\hline Early_income_decile(ages1-5) & $0.0393 * *$ & 2.75 & 0.0350 & 0.0865 & 1.72 & 0.7390 \\
\hline Number of siblings & 0.0056 & 0.18 & 0.0050 & $0.2431 * *$ & 2.18 & 2.5686 \\
\hline Parents own home & -0.1198 & -1.12 & -0.1069 & -0.4465 & -1.48 & -5.0218 \\
\hline Rural & 0.1610 & 1.50 & 0.1439 & $0.9643 * *$ & 2.56 & 12.7844 \\
\hline Prop family income benefits ${ }^{\mathrm{b}}$ & 0.2009 & 1.78 & 0.0018 & 0.6586 & 1.87 & 0.0610 \\
\hline Local_unemployment & 0.1413 & 1.42 & 0.1267 & 0.6383 & 1.77 & 8.2868 \\
\hline Proportion students continue ${ }^{\mathrm{b}}$ & $0.6090 * *$ & 2.46 & 0.0054 & -0.6072 & -0.70 & -0.0558 \\
\hline Class size & 0.0063 & 0.91 & 0.0056 & 0.0356 & 1.27 & 0.3352 \\
\hline Deviant peers & $-0.0628 * * *$ & -5.13 & -0.0555 & $0.1003 * *$ & 2.58 & 0.9787 \\
\hline Constant & $-4.6538 * * *$ & -4.05 & 1.2068 & $-9.1961 *$ & -2.27 & 6.2054 \\
\hline Variance of error term & & & & 0.6327 & 0.0198 (st & d. error) \\
\hline Number of observations $=$ & $598 \mathrm{I}$ & $\operatorname{R~chi~}^{2}(19)$ & 395.06 & 598 & $\operatorname{LR~chi}^{2}(18)$ & 74.6 \\
\hline $\begin{array}{l}\text { Left-censored: right censored } \\
\text { Pseudo } \mathrm{R}^{2}=\end{array}$ & $\begin{array}{l}56 \text { at } 0 \\
0.254\end{array}$ & 10 at 3 & & 0.269 & & \\
\hline Log likelihood = & $-578.943 \mathrm{~F}$ & rob $>$ chi $^{2}$ & 0.0000 & -101.476 & Prob $>$ chi $^{2}$ & $=0.0000$ \\
\hline
\end{tabular}


Table 3

Academic performance and school leaving, joint estimation

(Equation (2): Ave_grade (National Exam Grade at age 15))

(Equation (3): Dropout: 1=Left school at Age 16; $0=$ Enrolled in school at age 16)

\begin{tabular}{|c|c|c|c|c|c|c|}
\hline \multirow[t]{2}{*}{ Explanatory variables } & \multicolumn{3}{|c|}{$\begin{array}{c}\text { Average_grade } \\
\text { (Tobit) }\end{array}$} & \multicolumn{3}{|c|}{$\begin{array}{l}\text { Dropout } \\
\text { (Probit) }\end{array}$} \\
\hline & Coefficient & z-value & $\begin{array}{l}\text { Marginal } \\
\text { effects }^{\mathrm{a}}\end{array}$ & Coefficient & z-value & $\begin{array}{c}\text { Marginal } \\
\text { effects }^{\mathbf{a}}\end{array}$ \\
\hline \multicolumn{7}{|l|}{ Direct effects: } \\
\hline Ave_grade & & & & $-1.3091 * * *$ & -6.21 & -- \\
\hline \multicolumn{7}{|l|}{ Personal characteristics } \\
\hline Female & $0.1454 * *$ & 2.35 & 0.1312 & -0.4074 & -1.67 & -5.4996 \\
\hline Maori & 0.1483 & 1.37 & 0.1345 & 0.3636 & 1.22 & 2.1351 \\
\hline Pacific Islander & -0.1257 & -0.74 & -0.1125 & -0.3917 & -0.79 & -2.1505 \\
\hline IQ at age 8 & $0.0288 * * *$ & 13.39 & 0.0260 & & & $-0.2936^{\mathrm{b}}$ \\
\hline Mother_no_qualifications & $-0.1370 *$ & -2.17 & -0.1243 & 0.0439 & 0.20 & 1.8385 \\
\hline Mother tert_qualifications & 0.1135 & 1.53 & 0.1033 & 0.0382 & 0.11 & -0.7911 \\
\hline Father_no_qualifications & -0.0346 & -0.56 & -0.0312 & 0.0638 & 0.31 & 0.9723 \\
\hline Father_tert_qualifications & 0.1384 & 1.77 & 0.1263 & 0.3853 & 0.11 & -1.0259 \\
\hline Income_decile(ages 11-14) & $0.0575 * * *$ & 3.88 & 0.0520 & 0.0516 & 0.88 & -0.1019 \\
\hline Early_income_decile(ages1-5) & $0.0397 * *$ & 2.85 & 0.0359 & $0.1047 *$ & 2.28 & 0.6157 \\
\hline Number of siblings & 0.0157 & 0.51 & 0.0141 & $0.2218 *$ & 2.14 & 2.2492 \\
\hline Parents own home & -0.1443 & -1.39 & -0.1307 & -0.3200 & -1.12 & -1.6745 \\
\hline Rural & 0.1730 & 1.63 & 0.1568 & $0.8544 * *$ & 2.46 & 8.4641 \\
\hline Prop family income benefits ${ }^{\mathrm{c}}$ & $0.2593 *$ & 2.33 & 0.0023 & $0.7634 * *$ & 2.36 & 0.0458 \\
\hline Local_unemployment & 0.1385 & 1.41 & 0.1258 & 0.4480 & 1.36 & 3.4060 \\
\hline Proportion students continue ${ }^{c}$ & $0.5465 * *$ & 2.23 & 0.0049 & -0.0276 & -0.03 & -0.0575 \\
\hline Class size & 0.0082 & 1.20 & 0.0074 & 0.0324 & 1.28 & 0.2291 \\
\hline Deviant peers & $-0.0567 * * *$ & -4.66 & -0.0509 & $0.0717 *$ & 1.96 & 1.3910 \\
\hline Constant & $-4.4540 * * *$ & -3.90 & 1.2418 & $-7.0996 *$ & -1.90 & 5.6594 \\
\hline Variance of error term & $0.6315 * * *$ & 31.90 & $\mathrm{P}=0.000$ & & & \\
\hline Rho & $0.5170 * * *$ & 3.76 & $\mathrm{P}=0.000$ & & & \\
\hline Number of observations = & 598 & Wa & $\operatorname{chi} 2(18)=$ & 436.09 & & \\
\hline Log likelihood $=-676.051$ & & Prol & $\geq$ chi $^{2}$ & 0.0000 & & \\
\hline
\end{tabular}


Table 4

Reduced-form joint estimations

Ave_grade (National Exam Grade at age 15))

Dropout: $1=$ Left school at age 16; $0=$ Enrolled in school at age 16)

\begin{tabular}{|c|c|c|c|c|c|c|}
\hline \multirow[t]{2}{*}{ Explanatory variables } & \multicolumn{3}{|c|}{$\begin{array}{c}\text { Average_grade } \\
\text { (Tobit) }\end{array}$} & \multicolumn{3}{|c|}{$\begin{array}{c}\text { Dropout } \\
\text { (Probit) }\end{array}$} \\
\hline & Coefficient & $\begin{array}{c}\text { z- } \\
\text { value }\end{array}$ & $\begin{array}{l}\text { Marginal } \\
\text { effects }^{\mathrm{a}}\end{array}$ & Coefficient & $\begin{array}{c}\text { z- } \\
\text { value }\end{array}$ & $\begin{array}{c}\text { Marginal } \\
\text { effects }^{\mathrm{a}}\end{array}$ \\
\hline \multicolumn{7}{|l|}{ Personal characteristics } \\
\hline Female & $0.2077^{* * *}$ & 3.28 & 0.1833 & $-0.7848 * * *$ & -3.21 & -7.6856 \\
\hline Maori & 0.0898 & 0.80 & 0.0796 & 0.2820 & 0.88 & 3.1444 \\
\hline Pacific Islander & -0.1110 & -0.63 & -0.0970 & -0.1556 & -0.31 & -1.3779 \\
\hline IQ at age 8 & $0.0301 * * *$ & 14.18 & 0.0266 & $-0.0253 * *$ & -2.96 & -0.2388 \\
\hline Mother_no_qualifications & $-0.1441 *$ & -2.23 & -0.1280 & 0.2540 & 1.11 & 2.4212 \\
\hline Mother tert_qualifications & 0.1224 & 1.63 & 0.1091 & -0.2612 & -0.73 & -2.2526 \\
\hline Father_no_qualifications & -0.0366 & -0.58 & -0.0323 & 0.1067 & 0.48 & 1.0374 \\
\hline Father_tert_qualifications & 0.1303 & 1.65 & 0.1163 & -0.0299 & -0.09 & -0.2845 \\
\hline Income_decile (ages 11-14) & $0.0627 * * *$ & 4.16 & 0.0555 & -0.0287 & -0.48 & -0.2712 \\
\hline Early_income_decile(ages1-5) & $0.0394 * *$ & 2.76 & 0.0349 & 0.0581 & 1.18 & 0.5855 \\
\hline Number of siblings & 0.0018 & 0.06 & 0.0016 & $0.2051 *$ & 1.87 & 2.2408 \\
\hline Parents own home & -0.0922 & -0.86 & -0.0816 & -0.4056 & -1.41 & -4.7598 \\
\hline Rural & 0.1524 & 1.41 & 0.1352 & $0.7715 *$ & 2.19 & 10.1932 \\
\hline Prop family income benefits ${ }^{\mathrm{b}}$ & 0.1847 & 1.64 & 0.0016 & 0.3894 & 1.14 & 0.0382 \\
\hline Local_unemployment & 0.1316 & 1.32 & 0.1171 & 0.5255 & 1.53 & 6.8708 \\
\hline Proportion students continue ${ }^{\mathrm{b}}$ & $0.6389 * *$ & 2.57 & 0.0056 & -0.9312 & -1.11 & -0.0892 \\
\hline Class size & 0.0054 & 0.77 & 0.0048 & 0.0297 & 1.09 & 0.2993 \\
\hline Deviant peers & $-0.0644 * * *$ & -5.25 & -0.0565 & $0.1202 * *$ & 3.16 & 1.2535 \\
\hline Constant & $-4.6301 * * *$ & -4.02 & 1.1918 & -5.1013 & -1.27 & 6.2548 \\
\hline Variance of the error term: & 0.6349 & \multicolumn{2}{|c|}{ Std. Error=.0201 } & & & \\
\hline Rho & -0.2230 & \multicolumn{2}{|r|}{$\mathrm{P}=0.022$} & & & \\
\hline Number of observations $=5$ & 598 & \multicolumn{2}{|c|}{$\operatorname{LR} \operatorname{chi}^{2}(19)$} & 529.16 & & \\
\hline Log likelihood $=-683.040$ & & \multicolumn{2}{|c|}{ Prob $>$ chi $^{2}$} & 0.0000 & & \\
\hline
\end{tabular}

Note: *** Significant at .001; ** Significant at .01; * Significant at .05

a: The marginal effects are calculated for each individual and averaged across the sample. For more detail, see footnote 23.

The row with the constant term contains the average predicted value.

b: The marginal effect is approximated by increasing the value of the variable with 0.01 instead of 1 . 


\section{APPENDIX A}

Table A1

Definition of variables

School leaving at age 16

(Dropout)

Average school certificate grade at Age 15

(Ave_grade)

(Female)

(Maori)

Pacific Islander

(Pacific Islander)

Mother without qualifications

(Mother_no_qualifications)

Mother with tertiary qualifications

(Mother_tert_qualifications)

Father without qualifications

(Father_no_qualifications)

Father with Tertiary Qualifications

(Father_tert_qualifications)

Average income decile

(Income_decile (ages 11-14))

Early childhood average income decile (Early_income_decile (ages 1-5))

Parents own their own home (Parents own home)
Binary dependent variable:

1 for individuals who did not enroll beyond the postcompulsory level (age 16, usually at the $11^{\text {th }}$ grade (Sixth Form); 0 for those who continued.

The average value of all School Certificate $\left(10^{\text {th }}\right.$ grade, age 15) national level examination grades over all subjects taken with weightings of 3 for an A, 2 for a B, 1 for a $\mathrm{C}$ and 0 for a fail (D).

Binary $=0$ for a male; 1 for a female.

Binary=1 if ethnicity Maori.

Binary=1 if ethnicity Pacific Islander.

Binary $=1$ if child's mother does not have formal educational qualifications $\left(10^{\text {th }}\right.$ grade School Certificate or higher).

Binary $=1$ if a child's mother has a university or other tertiary qualification.

Binary=1 if a child's father does not have formal educational qualifications ( $10^{\text {th }}$ grade or higher).

Binary $=1$ if child's father has a university or other tertiary qualification.

Average income decile of the family when the child was between ages 11 and 14:

1 is consistently poor; 10 is consistently affluent.

Average income decile of the family when the child was between ages 1 and 5:

1 is consistently poor; 10 is consistently affluent.

Binary $=1$ if parents own their own home and the child is living at home at 15 years of age. 
Rural lifestyle

(Rural)

Proportion of family income from benefits (Prop family income benefits)

Registered unemployment (Local_unemployment)

Total intelligence quotient (IQ at age 8)

Proportion of students continuing (Proportion students continue)

Class size

(Class size)

Affiliation with deviant peers (Deviant peers)
Binary $=1$ if a child was not living in a main urban centre at 15 years of age.

The proportion (between 0 and 1) of the family's income derived from social welfare benefits.

Regional unemployment rate by gender in which each individual was living at 15 years of age. There were 8 regions and the corresponding levels of unemployment ranged between 5.9 and 12.1 per cent.

The child's measured total IQ score, testing cognitive performance at 8 years of age (revised Wechsler Intelligence Scale for Children).

Proportion of an individuals $10^{\text {th }}$ grade (Fifth Form) class within the data set continuing onto the $11^{\text {th }}$ grade. The relevant individual is excluded from the calculation.

Average class size in secondary school

Affiliation with deviant peers at age 15 based upon self-reported use of tobacco, alcohol, illicit drugs, other illegal behavior, etc. by friends: 0 to 10 , with 10 being the most deviant affiliations. 


\section{Notes}

${ }^{1}$ For example, academic achievement is shown to explain labor market success as reflected by earnings (see for example, Rumberger and Lamb, 2003; and Maani, 1997 and 2004 for New Zealand).

${ }^{2}$ In addition, the experience of countries such as Australia and New Zealand, which abolished university fees to increase access throughout the 1970s to the 1980s, has shown that the socioeconomic background of students is highly stable over time. For example, in Australia 10 years after the abolition of university fees, the socio-economic background of tertiary students had not changed, mainly representing children from fathers with a white-collar occupation and higher income levels (for example, Williams, 1987; and Anderson and Vervoon, 1983).

${ }^{3}$ Other earlier examples are Hanushek (1979), Case and Katz (1991), Duncan et. al (1998), and Montgomery (1991) for the US, and Prior and Beggs (1989) for Australia.

${ }^{4}$ Further information and other research using this data set can be found in Fergusson, Horwood and Lloyd (1991), and Fergusson and Lynskey (1993).

5 With new terminology implemented in 2002 in New Zealand, the years of study for children aged 5 to 18 are termed Year 1 to Year 13. In this paper, however, we are referring to the NorthAmerican equivalent years of kindergarten to the $12^{\text {th }}$ grade.

${ }^{6}$ After the year 2002, the School Certificate examination grades (also called the National Certificate of Educational Achievement (NCEA) examination) will include a significant internal assessment component provided at the school level. Therefore, the current data provide a good opportunity to use nationally comparable School Certificate results before these changes take effect.

${ }^{7}$ The original cohort of individuals in the survey consisted of 1265 individuals. The sample used in this study contains 713 observations to analyze the dropout before exams, and 598 observations for the joint estimations of School Certificate Examination at age 15 and school leaving at age 16 . The smaller sample used for age 16 is partly due to minor attrition over time, and partly due to missing values on variables of importance to this part of the study, such as average score, parental income, and school factors. Analysis indicates that the selected sample is slightly less likely to drop out of secondary school than the full sample (the probability is 0.0034 lower). A study for the New Zealand Treasury (Maloney, 1999) showed that attrition was related to some initial characteristics such as ethnicity and having a single parent. Nevertheless, comparisons with later Census data at both local and national levels show that the CHDS is still fairly representative of the population of children born around 1977.

${ }^{8}$ See Table A1 in Appendix A for a full list of variable descriptions.

${ }^{9}$ The IQ variable is correlated with both reading and mathematics scores at ages 8 and 9, but we 
found that the IQ score was consistently a better predictor of later academic performance than the other two measures. This possibly reflects the measurement of a broader set of skills.

${ }^{10}$ Maani and Kalb (2005) provide a detailed description of the economic theory and modeling.

${ }^{11}$ Evans and Schwab (1995), and Fuller, Manski and Wise (1982) include high school test scores either as a proxy for ability or as a control variable for earlier measures of learning in models of college attendance, and find strong support for the link. In that literature, academic performance is generally treated as exogenous. An exception is Light and Strayer (2000), who allow for nonzero correlation of error terms across a set of equations of quality of college attended and subsequent college graduation.

${ }^{12}$ The derivation of the joint likelihood function to be maximized for this joint model can be found in Maani and Kalb (2005), Appendix B.

${ }^{13}$ Our system of equations is based on the assumption that school leaving is not expected to affect academic performance directly. This assumption is supported by the sequence of the two events, where academic performance is measured about one year before the school leaving decision. Having only one of the observed dependent variables on the right hand side ensures that equations (2) and (3) are logically consistent (Maddala, 1983). However, if this assumption does not hold, the logical choice is to have academic performance depend on latent school leaving, given that the actual school leaving has not occurred yet. The joint reduced-form estimated implicitly accounts for such an effect.

${ }^{14}$ The variance in the Probit equation cannot be identified and is usually set to 1 . This approach has been followed here as well.

15 In addition, combining information on income deciles for different years is more straightforward than combining information on absolute levels of income. In the results section, we provide corresponding dollar values on the income effects.

${ }^{16}$ The marginal effects of the exogenous variables for the joint models are approximated by using a simulation approach. We draw 8000 times from the joint error distribution for each person in the sample and calculate school leaving and average score for each draw based on the individual's characteristics. The calculated values are averaged over the draws to obtain the expected value of the average score and school-leaving probability for each person, which is then averaged over the sample. For dummy variables, we set the value of one of the variables to 0 and compare the outcome to the calculation with the same variable set to 1 . We can then compute the marginal effect of this characteristic by taking the difference in predicted outcomes. For continuous variables, we increase the value of one characteristic with one unit for all individuals and recalculate the predicted outcome. The marginal effect for this particular characteristic is calculated as the difference between this predicted outcome and the predicted outcome at the observed value.

${ }^{17}$ For the teenage years, family income decile 1 corresponds with an average nominal weekly family income of around $\$ 300$, and decile 10 corresponds with $\$ 1635$. For early childhood, family income decile 1 corresponds with around $\$ 105$, and decile 10 with $\$ 410$ per week. 
18 Blau (1999) has examined the question of endogeneity of parental income and scores of childhood development. He notes that unobservable characteristics that are correlated with parental income may also explain child development. Applying different methods, especially fixed effects reflecting genetic or motivation factors (referred to as 'grandparent' effects, based on the characteristics of the child's maternal aunt) resulted in significantly larger permanent income effects on child development, but small and insignificant current income effects. Blau concluded that while the results were somewhat speculative, the evidence suggested that the estimated effects of permanent income are, if anything, biased downward in OLS estimations (p. 270).

${ }^{19}$ The estimated error correlation becomes larger negative, when important variables (such as IQ) are left out of the academic performance equation, which supports this conclusion.

${ }^{20}$ As noted earlier, the raw correlation between school leaving and the average income deciles is negative. The relationship only becomes positive after controlling for several other characteristics.

${ }^{21}$ IQ was not included in the final version of the single-equation model presented here. However, in an alternative specification where IQ was included, the effect of IQ was insignificant and the calculated marginal effect was much smaller ( -0.13 percentage points) than in the joint models. 